\title{
Maggot Debridement Therapy for Peripheral Arterial Disease
}

Kimihiro Igari, MD, Takahiro Toyofuku, MD, PhD, Hidetoshi Uchiyama, Shinya Koizumi, Koji Yonekura,
Toshifumi Kudo, MD, PhD, Masatoshi Jibiki, MD, PhD, Norihide Sugano, and Yoshinori Inoue, MD, PhD

Introduction: Maggots are potent debriding agents capable of removing necrotic tissue and slough; however, it is still unclear which wounds are most likely to benefit from maggot debridement therapy (MDT). Thus, we performed this retrospective review to gain insight into the patient and therapy characteristics influencing outcome.

Patients and Methods: We reviewed patients with foot ulcers caused by critical limb ischemia, encountered during the period between June 2005 and May 2010. The treatment outcomes were defined as effective or ineffective.

Results: There were 16 patients with 16 leg ulcers. The patients were 13 men and 3 women, with an average age of 67.2 years (range, $47-85$ years). Ten (63\%) of the 16 ulcers were treated effectively. According to univariate analyses, an ankle brachial pressure index $(\mathrm{ABI})$ lower than $0.6(\mathrm{p}=0.03)$ had a negative impact on the outcome of MDT; however, outcome was not influenced by gender, obesity, ischemic heart disease, diabetes mellitus, hemodialysis, smoking, or laboratory findings.

Conclusions: Some patient characteristics, such as gender, obesity, ischemic heart disease, diabetes mellitus, hemodialysis, and smoking, do not seem to contraindicate eligibility for MDT. However, a limb with an ABI lower than 0.6 is less likely to benefit. (*English Translation of J Jpn Coll Angiol 2011; 51: 209-213.)

Keywords: peripheral arterial disease, maggot debridement therapy, foot ulcer, necrotic foot

\section{INTRODUCTION}

Come ulcerative and gangrenous lesions associated $\checkmark$ with peripheral arterial disease (PAD) resist treatment and often necessitate major limb amputation. Causes of the refractoriness of such lesions include severe ischemia and infection by multi-drug-resistant bacteria. Recently, maggot debridement therapy (MDT) using

Department of Vascular Surgery, Tokyo Medical and Dental University, Tokyo, Japan

Received: April 15, 2013; Accepted: April 21, 2013

Corresponding author: Kimihiro Igari, MD. Department of Vascular Surgery, Tokyo Medical and Dental University, 1-5-45 Yushima,

Bunkyo-ku, Tokyo 113-8510, Japan

Tel: +81-3-5803-5255, Fax: +81-3-3817-4126

E-mail: igari.srg1@tmd.ac.jp

*This article is English Translation of J Jpn Coll Angiol 2011; 51:

209-213. medical sterile maggots has attracted attention due to its possible effectiveness for the treatment of refractory ulcers. Maggots have been known to be effective for the treatment of ulcers for centuries, ${ }^{1)}$ and Baer used them for the treatment of chronic osteomyelitis in children and reported its effectiveness for the first time. ${ }^{2)}$ In Japan, Mitsui $^{3)}$ first reported cases of severe ischemic ulcer of the lower limbs that responded to MDT. On the basis of these reports, our department began to treat foot ulcer and gangrene by MDT in 2005 and has treated 16 limbs of 16 patients to date.

In this study, we evaluated the therapeutic effects of MDT at our department.

\section{Subjects ANd Methods}

The subjects were 16 patients (16 limbs) who underwent MDT between June 2005 and May 2010. MDT was 
indicated for ulcerated or gangrenous lesions of the toes or foot associated with PAD. The causative diseases were arteriosclerosis obliterans in 15 and Buerger disease in 1 . The sites of the lesions were the toes in 8 limbs, foot in 7 , and heel in 1. Culturing of samples from the lesions led to bacteria detection in 15 of the 16 patients, and the isolates were predominantly methicillin-resistant Staphylococcus aureus (MRSA) (14 patients). The depth of the lesion, which was defined as deep when bone or tendon was exposed and as superficial when the lesion was shallower, was deep in 11 and superficial in 5. As comorbidities, diabetes mellitus was observed in 13 patients $(81 \%)$, hemodialysis in $7(43 \%)$, ischemic heart disease in $4(25 \%)$, and cerebral infarction in $2(12 \%)$ (Table 1). MDT was performed by placing second instar larvae of Lucilla sericata purchased from the Japan Maggot Company on the lesion at 5-10 maggots $/ \mathrm{cm}^{2}$ and covering the entire lesion with a commercially available stocking (stocking method) (Fig. 1). As a basic strategy, a course of therapy (1 treatment), which was finished in 3-4 days, was repeated 2 times/week until a debridement effect was observed.

The therapeutic effect was compared according to: (1) the characteristics of patients: age, gender, body mass index (BMI), ischemic heart disease, diabetes mellitus, smoking history (positive when the patient had a history of smoking within 6 months before the beginning of therapy), depth of wound (deep, superficial), and blood test results before the beginning of therapy (hemoglobin, white blood cell, c-reactive protein, albumine); and (2) therapeutic factors: the ankle pressure (AP), ankle brachial pressure index $(\mathrm{ABI})$, transcutaneous oxygen tension $(\mathrm{tcPO})$, revascularization, use of antibiotics, number of MDT treatments, total number of maggots used, and mean number of maggots used per treatment. The treatment was considered effective when the ulcer size was reduced or when a secondary wound closing procedure such as skin grafting or skin flap surgery could be performed, and not effective when the ulcer showed no change, was exacerbated, or when major amputation was necessary. The treatment was effective in $10(63 \%)$ and not effective in $6(37 \%)$, with $3(18 \%)$ requiring major amputation.

Statistical analysis was performed using the MannWhitney U-test for comparison of the mean values between the 2 groups and the $\chi^{2}$-test for examination of the independence of each group at the $\mathrm{p}<0.05$ level of significance.
Table 1 The case of maggot debridement therapy

\begin{tabular}{lr}
\hline Characterisitcs & Case \\
\hline Cause & \\
Areteriosclerosis obliterans & 15 \\
Buerger's disease & 1 \\
Site of wound & \\
Toe & 8 \\
Foot & 7 \\
Heel & 1 \\
Comorbidity & \\
Diabetes mellitus & 13 \\
Hemodialysis & 7 \\
Ischemic heart disease & 4 \\
Cerebral infarction & 2 \\
Outcome & \\
Effect & 10 \\
No effect & 6 \\
Major amputation & 3 \\
\hline
\end{tabular}

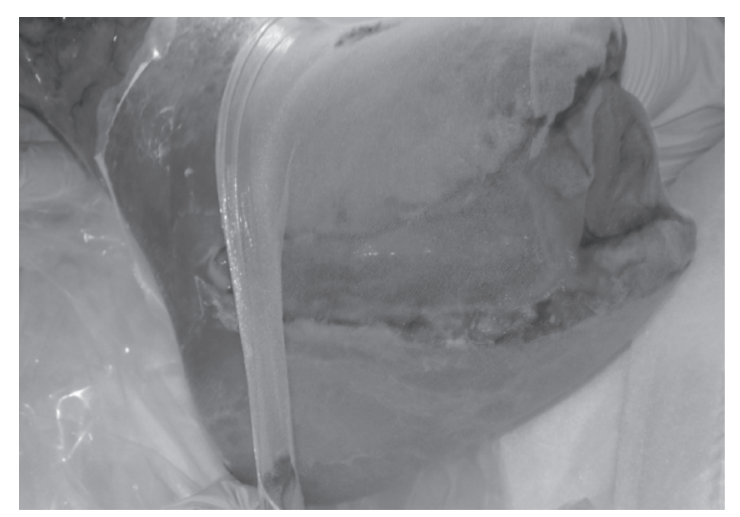

Fig. 1 The procedure of maggot debridement therapy. Maggots were left on the wound and covered with net mesh.

\section{Results}

\section{(1) Characteristics of patients (Table 2)}

The patients consisted of 13 males and 3 females, with a mean age of 67.2 years ( $47-85$ years). The BMI was $20.1 \pm 2.51 \mathrm{~kg} / \mathrm{m}^{2}$ in the effect group and $19.3 \pm 1.70$ $\mathrm{kg} / \mathrm{m}^{2}$ in the no-effect group. No clear difference was observed between the 2 groups in gender, age, the BMI, or the presence or absence of comorbidities, i.e., ischemic heart disease, hemodialysis, and diabetes mellitus. A smoking history was positive in $1(10 \%)$ in the effect group and 2 (34\%) in the no-effect group. The depth of the wound was deep in $7(70 \%)$ in the effect group and $4(67 \%)$ in the no-effect group, with no clear difference between the two groups. There was no clear difference in the blood test results before MDT between the two groups. 
Table 2 The characteristics of patients who underwent maggot debridement therapy

\begin{tabular}{|c|c|c|c|}
\hline Factor & Effect & No effect & $\mathrm{p}$ value \\
\hline Age (y.o.) & $67.8 \pm 10.8$ & $66.3 \pm 12.5$ & 0.74 \\
\hline Gender (Male:Female) & $7: 3(70 \%)$ & $6: 0(100 \%)$ & 0.14 \\
\hline BMI $\left(\mathrm{kg} / \mathrm{m}^{2}\right)$ & $20.1 \pm 2.51$ & $19.3 \pm 1.70$ & 0.66 \\
\hline Diabetes mellitus (+:-) & $9: 1(90 \%)$ & $4: 2(67 \%)$ & 0.25 \\
\hline Smoking (+:-) & $1: 9(10 \%)$ & $2: 4(34 \%)$ & 0.25 \\
\hline Ischemic heart disease $(+:-)$ & $2: 8(20 \%)$ & $2: 4(33 \%)$ & 0.55 \\
\hline Hemodialysis (+:-) & $4: 6(40 \%)$ & $3: 3(50 \%)$ & 0.69 \\
\hline Depth of wound (Deep:Superficial) & $7: 3(70 \%)$ & $4: 2(67 \%)$ & 0.89 \\
\hline $\mathrm{Hb}(\mathrm{g} / \mathrm{dl})$ & $9.17 \pm 0.91$ & $9.70 \pm 0.76$ & 0.28 \\
\hline WBC $(/ \mu 1)$ & $8,160 \pm 1,960$ & $8,270 \pm 2,570$ & 0.79 \\
\hline CRP (mg/dl) & $4.76 \pm 3.61$ & $6.15 \pm 5.96$ & 0.66 \\
\hline $\operatorname{Alp}(\mathrm{g} / \mathrm{dl})$ & $3.01 \pm 0.39$ & $3.15 \pm 0.52$ & 0.45 \\
\hline
\end{tabular}

BMI: body mass index; Hb: hemoglobin; WBC: white blood cell; CRP: C-reactive protein; Alp: albumin

Table 3 The treatment characteristics of patients treated with maggot debridement therapy

\begin{tabular}{|c|c|c|c|}
\hline Factor & Effect & No effect & $\mathrm{p}$ value \\
\hline Revascularization (Yes:No) & $10: 0(100 \%)$ & $3: 3(50 \%)$ & $0.01^{*}$ \\
\hline AP $(\geq 70:<70)$ (except unmeasured) & $4: 0(100 \%)$ & $1: 3(25 \%)$ & $0.03^{*}$ \\
\hline ABPI $(\geq 0.6:<0.6)$ (except unmeasured) & $4: 0(100 \%)$ & $1: 3(25 \%)$ & $0.03^{*}$ \\
\hline $\mathrm{tcPO}_{2}(\geq 30:<30)$ (except unmeasured) & $5: 2(71 \%)$ & $2: 3(40 \%)$ & 0.56 \\
\hline ABPI ( $\geq 0.6$ or $\left.\mathrm{tcPO}_{2} \geq 30\right)$ (except unmeasured) & $7: 1(88 \%)$ & $3: 3(50 \%)$ & 0.12 \\
\hline Antibiotics (Yes:No) & $7: 3(70 \%)$ & $4: 2(67 \%)$ & 0.89 \\
\hline Number of treatments with MDT & $3.8 \pm 3.1$ & $2.3 \pm 1.5$ & 0.39 \\
\hline Total maggots & $277 \pm 277$ & $208 \pm 149$ & 0.55 \\
\hline Maggots per treatment & $79.4 \pm 24.2$ & $91.6 \pm 20.4$ & 0.33 \\
\hline
\end{tabular}

AP: ankle pressure; ABPI: ankle brachial pressure index; $\mathrm{tcPO}_{2}$ : transcutaneous oxygen tension; MDT: maggot debridement therapy; *: statistically significant $(\mathrm{p}<0.05)$

(2) Therapeutic factors (Table 3)

Revascularization was performed before MDT in 10 $(100 \%)$ in the effect group and $3(50 \%)$ in the no-effect group. The AP was $70 \mathrm{mmHg}$ or higher before MDT in $4(100 \%)$ of the 4 patients in the effect group and in $1(25 \%)$ of the 4 patients in the no-effect group, with a significant difference $(p=0.03)$ after the exclusion of patients in whom measurement was impossible. Similarly, the ABI was 0.6 or higher before MDT in $4(100 \%)$ of the 4 patients in the effect group and in $1(25 \%)$ of the 4 patients in the no-effect group, with a significant difference $(p=0.03)$ after the exclusion of patients in whom the measurement was impossible. Six of the 10 patients in the effect group and 2 of the 6 patients in the no-effect group were excluded because measurement of the ABI was impossible due to ulceration or pain, or because the ABI was markedly elevated due to severe arterial calcification. Also, the $\mathrm{tcPO}_{2}$ was $30 \mathrm{mmHg}$ or higher in $5(71 \%)$ of the 7 patients in the effect group and $2(40 \%)$ of the 5 patients in the no-effect group, being higher in the effect group (range: $20-72 \mathrm{mmHg}$, median: $37 \mathrm{mmHg}$ ), but the difference was not significant. Antibiotics were used during MDT in $7(70 \%)$ in the effect group and $4(67 \%)$ in the no-effect group, with no clear difference. The mean number of treatments was $3.8 \pm 3.1$ in the effect group and $2.3 \pm 1.5$ in the no-effect group and was higher in the effect group, but the difference was not significant. The number of maggots used per treatment was $79.4 \pm 24.2$ in the effect group and $91.6 \pm 20.4$ in the no-effect group, and the total number of maggots used was $277 \pm 227$ and $208 \pm 149$, respectively, with no significant difference in either parameter.

\section{Discussion}

Since the 1990s, infected ulcers resistant to antibiotics 
have appeared due to the overuse of antibiotics, and diseases that cause ulcers such as diabetes and arteriosclerosis have increased, causing an increase in intractable ulcers that follow unfavorable courses. MDT has attracted attention as a treatment for such intractable ulcers. Characteristic effects of MDT include: removal of necrotic tissue, promotion of granulation, control of infection, and sterilization of the wound. $\left.{ }^{4}\right)$ While its therapeutic effects vary among reports, MDT has been effective in about $80 \%-90 \%$ of patients. ${ }^{5-7)}$

MDT has also been reported to be effective for the treatment of pressure ulcer, ${ }^{8)}$ burn injury, ${ }^{9)}$ osteomyelitis, ${ }^{10)}$ diabetic ulcer, ${ }^{11)}$ ulcers associated with venous stasis, ${ }^{12)}$ MRSA infection, ${ }^{13)}$ and chronic intractable ulcers. ${ }^{14)}$ Age has been suggested as a factor that affects the therapeutic effect of MDT, ${ }^{15)}$ but these factors have not been evaluated in detail. In this study, their effects on the effectiveness of MDT were evaluated by dividing them into patient and therapeutic factors. Since the therapeutic effect of MDT differed significantly according to the AP ( $\geq 70$ vs. $<70 \mathrm{mmHg}$ ) and $\mathrm{ABI}(\geq 0.6$ vs. $<0.6$ ), they are considered to be factors that affect the effectiveness of MDT. Generally, the ABI often shows a value higher than the true value in patients with arterial calcification due to diabetes or hemodialysis. Since no clear difference was observed in the prevalence of diabetes or hemodialysis between the effect and no-effect groups in this study, the $\mathrm{ABI}$ is considered to be a factor that affects the therapeutic effect of MDT. We also evaluated the effect of the $\mathrm{tcPO}_{2}$, which is an index of tissue blood flow. A high wound healing rate has been reported to be expected in patients with a tc $\mathrm{PO}_{2} \geq 30 \mathrm{mmHg},{ }^{16}$ ) but no significant difference was noted in our study by comparing the therapeutic effect between $\mathrm{tcPO}_{2} \geq 30$ and $<30 \mathrm{mmHg}$. Also, MDT was not effective in 3 patients despite a sufficient tissue blood flow with an $\mathrm{ABI} \geq 0.6$ or a $\mathrm{tcPO}_{2} \geq 30 \mathrm{mmHg}$. In these patients, the depth of the wound was deep in 2 and superficial in 1, with no significant difference compared with the effect group, and no clear difference was noted in other patient factors. However, in these patients, the mean number of treatments of MDT was 1.6, and the mean number of maggots used was 120 , both of which were less than half the mean values of all patients. This suggests that insufficient repetition of MDT was a cause of the poor therapeutic effect. Moreover, while these 3 patients belonged to the no-effect group, they avoided major leg amputation, and this may have been due to MDT. In addition, gender has been reported not to affect the therapeutic outcome, ${ }^{17)}$ and the results of our study were in agreement with this report. From these observations, it is regrettable that MDT was also performed for patients with an insufficient tissue blood flow in a period early after its introduction to our department. MDT was often more successful in a late period when we considered the relationship between the success rate of MDT and tissue blood flow and performed MDT after sufficient tissue blood flow had been achieved by revascularization. Since MDT is a treatment for infection rather than one to improve regional blood flow, it should be applied to patients with an intact blood flow.

A problem with MDT is that there is no standard method for evaluation of the therapeutic effect. There are evaluation methods including a scoring system and categorization method, ${ }^{18,19)}$ and comparison among reports is made difficult by the diversity of the evaluation method. Also, while Wolff, et al. ${ }^{5)}$ noted an effect of MDT in $79 \%$ of patients, their subjects included patients with PAD (51\%), diabetic ulcer (39\%), and venous stasis ulcer (14\%); this heterogeneity of subjects is another factor that makes comparison among reports difficult. Therefore, the establishment of an objective index of the therapeutic effectiveness of MDT and reports of therapeutic outcomes in different diseases are awaited.

\section{Conclusion}

In this study, we evaluated the therapeutic outcomes of MDT in ulcerated or gangrenous lesions of the lower limbs. An adequate regional blood flow is important for MDT to be effective. Also, the therapeutic effect of MDT was suggested to be enhanced by its repetition. However, as evaluation of the effects of MDT is difficult due to the absence of a standardized evaluation method, the establishment of such a method is awaited.

\section{Disclosure Statement}

None.

\section{REFERENCES}

1) Church JC. The traditional use of maggots in wound healing, and the development of larva therapy (biosurgery) in modern medicine. J Altern Complement Med 1996, 2: 525-7.

2) Baer WS. The treatment of chronic osteomyelitis with the maggot (larva of the blow fly). J Bone Joint Surg Am 1931; 13: 438-75.

3) Mitsui H.A case of severe ischemic ulcer of the leg treated 
with sterile maggots - Combination with a lipo-PGE1 preparation-Angiol Frontier 2005; 4: 243-7.

4) Sherman RA, Hall MJ, Thomas S. Medicinal maggots: an ancient remedy for some contemporary afflictions. Annu Rev Entomol 2000; 45: 55-81.

5) Wolff H, Hansson C. Larval therapy - an effective method of ulcer debridement. Clin Exp Dermatol 2003; 28: 134-7.

6) Courtenay M, Church JC, Ryan TJ. Larva therapy in wound management. J R Soc Med 2000; 93: 72-4.

7) Mumcuoglu KY, Ingber A, Gilead L, et al. Maggot therapy for the treatment of intractable wounds. Int J Dermatol 1999; 38: 623-7.

8) Sherman RA. Maggot versus conservative debridement therapy for the treatment of pressure ulcers. Wound Repair Regen 2002; 10: 208-14.

9) Namias N, Varela JE, Varas RP, et al. Biodebridement: a case report of maggot therapy for limb salvage after fourth-degree burns. J Burn Care Rehabil 2000; 21: 254-7.

10) Sherman RA, Pechter EA. Maggot therapy: a review of the therapeutic applications of fly larvae in human medicine, especially for treating osteomyelitis. Med Vet Entomol 1988; 2: 225-30.

11) Yates I, Fox M, Crewdson M, et al. Larvae - a key member of the multidisciplinary foot team? The
Diabetic Foot J 2003; 6: 166-71.

12) Sherman RA, Tran JM, Sullivan R. Maggot therapy for venous stasis ulcers. Arch Dermatol 1996; 132: 254-6.

13) Mumcuoglu KY, Ingber A, Gilead L, et al. Maggot therapy for the treatment of diabetic foot ulcers. Diabetes Care 1998; 21: 2030-1.

14) Mumcuoglu KY. Clinical applications for maggots in wound care. Am J Clin Dermatol 2001; 2: 219-27.

15) van Rijswijk L. Full-thickness leg ulcers: patient demographics and predictors of healing. Multi-Center Leg Ulcer Study Group. J Fam Pract 1993; 36: 625-32.

16) Ballard JL, Eke CC, Bunt TJ, et al. A prospective evaluation of transcutaneous oxygen measurements in the management of diabetic foot problems. J Vasc Surg 1995; 22: 485-90; discussion 490-2.

17) Oyibo SO, Jude EB, Tarawneh I, et al. The effects of ulcer size and site, patient's age, sex and type and duration of diabetes on the outcome of diabetic foot ulcers. Diabet Med 2001; 18: 133-8.

18) Wollina U, Karte $K$, Herold $C$, et al. Biosurgery in wound healing - the renaissance of maggot therapy. J Eur Acad Dermatol Venereol 2000; 14: 285-9.

19) Church JCT, Courtenay M. Maggot debridement therapy for chronic wounds. Int J Low Extrem Wounds 2002; 1: 129-34. 